\title{
Ethylene polymerization over chromium supported onto SBA-15 mesoporous materials
}

\author{
G. Calleja, J. Aguado, A. Carrero, J. Moreno. \\ Department of Chemical, Environmental and Materials Technology. ESCET. \\ Rey Juan Carlos University. C/ Tulipán s/n 28933, Móstoles (Madrid), Spain.
}

\section{Published on: \\ Studies in Surface Science and Catalysis 158 (2005) 1453-1460 doi:10.1016/S0167-2991(05)80497-5}

Ethylene polymerization catalysts have been prepared by incorporation of chromium (III) acetylacetonate onto siliceous SBA-15 swelled mesoporous materials. Catalysts characterization includes DRX, FTIR, UV-vis spectroscopy, nitrogen physisorption, TGA and ICP analysis. Chromium anchorage through H-bonds was observed in Cr/SBA-15 catalyst prepared by incipient wetness impregnation. On the contrary, when catalysts were prepared by grafting, a ligand exchange reaction may occur. For similar chromium contents, catalyst prepared by grafting showed higher polymerization activity than catalyst prepared by incipient wetness impregnation. Regarding polymer properties, Cr/SBA-15 catalyst prepared by impregnation gave polyethylene with slightly higher molecular weight, polydispersity, bulk density and melting temperature than polyethylene obtained from grafted catalyst.

\section{INTRODUCTION}

In the early 1950's J.P. Hogan and R. L. Banks discovered that chromium oxide supported on silica and other carriers catalyzed the polymerization of olefins to high polymers [1]. Since then, this catalytic system has showed an important development and different varieties of chromium-based catalysts are used in the Phillips polymerization process, because of the wide variations in the polymer properties depending upon the catalyst molecular structure [2]. Today, chromium catalysts are responsible for the commercial production of more than one third of all polyethylene sold worldwide [3]. The activity of these polymerization catalysts is very sensitive to the textural properties of the supports and particularly to their porosity [4]. Therefore, an adequate control of the porous structure of the supports during their synthesis gives an opportunity to prepare new polymerization catalysts.

Recently, the synthesis of new mesoporous silica, SBA-15 has been reported under acidic conditions using triblock copolymers as structure directing agents [5]. The narrow, controlled pore size distribution of these ordered hexagonal materials as well as their large pore openings $(5-30 \mathrm{~nm})$ and high surface areas $\left(600-1000 \mathrm{~m}^{2} / \mathrm{g}\right)$ are attractive properties that make SBA-15 mesoporous materials useful as catalyst supports for polymerization processes.

Besides, the method of chromium incorporation employed could also influence on the polymerization behaviour of Phillips catalysts. Conventionally, chromium oxide systems supported on silica and alumina systems have been prepared by impregnation of the dispersed support with a solution of chromium compounds, followed by their transformation to the catalytically active phase upon thermal treatment. However, gas phase deposition and grafting of chromium complexes onto reactive surface structures are two alternatives to traditional 
incipient wetness impregnation method, which allow obtaining catalytic systems with different properties [6-7].

We compare here the properties and ethylene polymerization behaviour of $\mathrm{Cr} / \mathrm{SBA}-15$ catalysts prepared by incipient wetness impregnation and grafting methods.

\section{EXPERIMENTAL}

Siliceous SBA-15 mesoporous support was synthesized in the presence of trimethylbencene (TMB) as swelling agent, according to the process previously reported [5]. This material, after drying and calcination at $550^{\circ} \mathrm{C}$, was stirred with different solutions of chromium (III) acetylacetonate, $\mathrm{Cr}(\mathrm{acac})_{3}$, in toluene $(5,15,35$ and 56 grams of $\mathrm{Cr}$ per 100 grams of solid) for 24 hours under reflux. Then, solids were recovered by filtration and intensively washed with toluene. Besides, one additional SBA-15 sample was incipient wetness impregnated with a fixed amount of $\mathrm{Cr}(\mathrm{acac})_{3}$ in toluene to get $1 \mathrm{wt} \%$ chromium loading. Finally, catalysts were calcined with air on a fluidized bed reactor up to $600{ }^{\circ} \mathrm{C}$.

Textural properties of mesoporous materials were determined by means of nitrogen adsorption-desorption isotherms at $77 \mathrm{~K}$ using an adsorption porosimeter (Micromeritics, Tristar 3000). Pore size was obtained from the maximum of BJH pore size distribution. X-ray powder diffraction (XRD) data were acquired on a Philips diffractometer using $\mathrm{Cu} \mathrm{K} \alpha$ radiation. Fourier transform IR (FT-IR) spectra of fresh catalysts were recorded on a Mattson Infinity Series spectrophotometer using the potassium bromide wafer technique. Diffuse reflectance UV-VIS spectra (DRS) of as-synthesized and calcined chromium mesoporous materials were obtained under ambient conditions on a CARY-1 spectrophotometer equipped with a diffuse reflectance accessory in the wavelength range of 300-700 nm. A halon white reflectance standard was used as a reference material. Thermogravimetric measurements (TGA) were performed in air flow on a TA instrument SDT 2960 thermobalance, with a heating rate of $5^{\circ} \mathrm{C} / \mathrm{min}$ up to $700^{\circ} \mathrm{C}$. Catalysts chemical composition was measured by ICPatomic emission spectroscopy on a Varian Vista AX CD system. The carbon content of the as-synthesized catalysts was determined with an elemental Vario EL III analyzer by burning at $1150^{\circ} \mathrm{C}$.

Ethylene polymerizations were carried out in a 2-litre stainless steel stirred Autoclave Engineers apparatus. Reaction conditions were 600 r.p.m., $85{ }^{\circ} \mathrm{C}, 35$ bar of ethylene pressure, 5.0 bar of hydrogen and $0.5 \mathrm{~mol}$ of 1-hexene using isobutane as solvent. The resulting polyethylene was recovered, filtered and washed with acetone.

DSC analysis of the obtained polymers were recorded from 50 to $180{ }^{\circ} \mathrm{C}$ (heating rate $=10^{\circ} \mathrm{C} / \mathrm{min}$ ) with a Mettler Toledo DSC822 apparatus. High load melt index (HLMI) values were determined at $190{ }^{\circ} \mathrm{C}$ with a weight load of $21.6 \mathrm{~kg}$ using a Ceast 6542/002 extrusion plastometer. The bulk density of polyethylene was determined from the dry weight and the volume of the sample in a volumetric tube by liquid displacement. Molecular weights and molecular weight distributions of the polymers were determined by size-exclusion chromatography at $145^{\circ} \mathrm{C}$ on a Waters $150 \mathrm{C}$ Plus instrument, using 1,2,4-dichlorobencene as a mobile phase. The column set consisted of one PL-Gel 10 $\mu \mathrm{m}$ Mixed B (300 x $7.5 \mathrm{~mm})$ and another Polymer PL-Gel $10 \mu \mathrm{m}$ 10E6A (300 x 7.5 mm).

\section{RESULTS AND DISCUSSION}

\subsection{Catalysts Characterization}

The X-ray diffraction pattern of calcined SBA-15 support prepared with TMB showed a (100) peak and (110), (200) and (210) signals at d spacings of 132, 105, 98 and $74 \AA$, 
respectively. These reflections are associated with $\mathrm{p} 6 \mathrm{~mm}$ hexagonal symmetry typical of SBA-15 materials [5], although the presence of TMB as a swelling micelle agent, leads to structures less organized as evidenced by weak XRD peaks [8]. The prepared catalysts are listed in Table 1, they are denoted as SBA-nG or SBA-nI for grafted or impregnated samples, respectively. The number designed by " $n$ " corresponds to the chromium loading (wt \%) of each catalyst.

TABLE 1

Grafting efficiencies and textural properties of Cr/SBA-15 catalysts

\begin{tabular}{lcccccc}
\hline Catalysts & $\begin{array}{c}\text { Grafting } \\
\text { solution } \\
\left(\frac{g \operatorname{cr}(\text { solution })}{g \text { support }}\right) \times 100\end{array}$ & $\begin{array}{c}\text { Chromium } \\
\text { content } \\
(\text { wt } \%)\end{array}$ & $\begin{array}{c}\text { Grafting } \\
\text { Efficiency } \\
(\%)\end{array}$ & $\begin{array}{c}\text { Surface } \\
\text { Area } \\
\left(\mathrm{m}^{2} / \mathrm{g}\right)\end{array}$ & $\begin{array}{c}\text { Pore } \\
\text { Volume } \\
(\mathrm{cc} / \mathrm{g})\end{array}$ & $\begin{array}{c}\text { Pore Size } \\
(\AA)\end{array}$ \\
\hline SBA-15 & -- & -- & -- & 613 & 2.20 & 249 \\
SBA-0.24G & 2.5 & 0.24 & 9.6 & 593 & 2.10 & 249 \\
SBA-0.42G & 15 & 0.42 & 2.8 & n.d & n.d & n.d \\
SBA-0.72G & 35 & 0.72 & 2.1 & 523 & 1.94 & 249 \\
SBA-0.92G & 56 & 0.92 & 1.6 & 518 & 1.96 & 252 \\
SBA-0.99I & -- & 0.99 & -- & 537 & 1.99 & 247 \\
\hline
\end{tabular}

n.d. $=$ not determined

It can be observed that the chromium anchored onto the calcined SBA-15 supports increased with the initial chromium amount contained in the grafting solution, although chromium incorporation degrees (grafting efficiencies) were always below $10 \%$. This fact can be explained taking into account that the affinity of $\mathrm{M}^{\mathrm{n}+}(\mathrm{acac})_{\mathrm{n}}$ complexes from the liquid phase with the silica surface depends on the shape, stability and metal ions in the complex [9]. In this case, chromium acetylacetonate is an octahedral complex having a high thermal stability and consequently low chemical reactivity towards the support. Besides, the octahedral geometry should generate steric hindrance for bonding to silica surface. The nitrogen adsorption/desoption isotherms at $77 \mathrm{~K}$ for calcined SBA-15 support and chromium catalysts (Fig. 1) belonged to type IV typical for mesoporous materials, with a sharp inflexion at a relative pressure around 0.9. Textural properties summarized in Table 1, pointed to a little decrease in both surface area and pore volume with chromium incorporation, while pore size remained almost unaltered.

UV-Vis diffuse reflectance spectra of the as-synthesized SBA-15 chromium supported catalysts are compared with bulk chromium (III) acetylacetonate spectrum in Fig. 2(I). SBA0.99I sample, prepared by incipient wetness impregnation, and bulk $\mathrm{Cr}(\mathrm{acac})_{3}$ presented the same colour (violet) and similar spectra with typical $\mathrm{Cr}$ (III) d-d absorption bands centred at 325,390 and $560 \mathrm{~nm}$ which can be attributed to ${ }^{4} \mathrm{~A}_{2 \mathrm{~g}} \rightarrow{ }^{4} \mathrm{~T}_{2 \mathrm{~g}}(\mathrm{~F}),{ }^{4} \mathrm{~A}_{2 \mathrm{~g}} \rightarrow{ }^{4} \mathrm{~T}_{1 \mathrm{~g}}(\mathrm{~F})$ and ${ }^{4} \mathrm{~A}_{2 \mathrm{~g}} \rightarrow$ ${ }^{4} \mathrm{~T}_{2 \mathrm{~g}}(\mathrm{P})$ transitions in the pseudo-octahedral coordinated chromium (III) ions, respectively [10]. Nevertheless, catalysts prepared by grafting (SBA-0.92G and SBA-0.72G) showed a greenish colour and the band placed at $390 \mathrm{~nm}$ had almost disappeared from the DRS UV-Vis spectra. Both differences indicated a change in chromium electron configuration [11]. The same trend was observed for SBA-0.42G, and SBA-0.24G catalysts (not shown). 


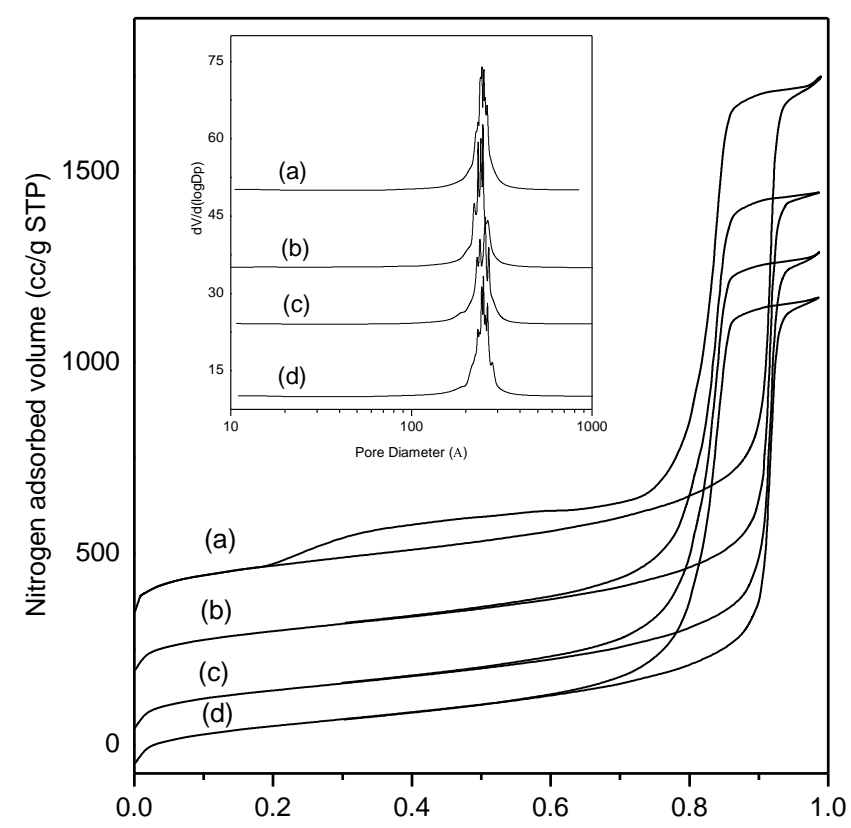

Fig.1. $\mathrm{N}_{2}$ adsorption/desorption isotherms of: (a) SBA-15 support, (b) SBA-0.99I, (c) SBA-0.92G, (d) SBA-0.72G.

The calcination of the as-synthesized samples resulted in the complete disappearance of d-d bands (Fig. 2 (II)) caused by the oxidation of Cr (III) species to $\mathrm{Cr}$ (VI). Hexavalent chromium species were characterized by two absorption bands centred at 350 and $460 \mathrm{~nm}$, which can be assigned to the $\mathrm{O} \rightarrow \mathrm{Cr}^{6+}$ charge transfer transitions of chromate and dichromate species [12]. The absence of $\mathrm{Cr}_{2} \mathrm{O}_{3}$ bands at $560 \mathrm{~nm}$ indicated the total oxidation of $\mathrm{Cr}^{3+}$ to $\mathrm{Cr}^{6+}$ during the calcination step.
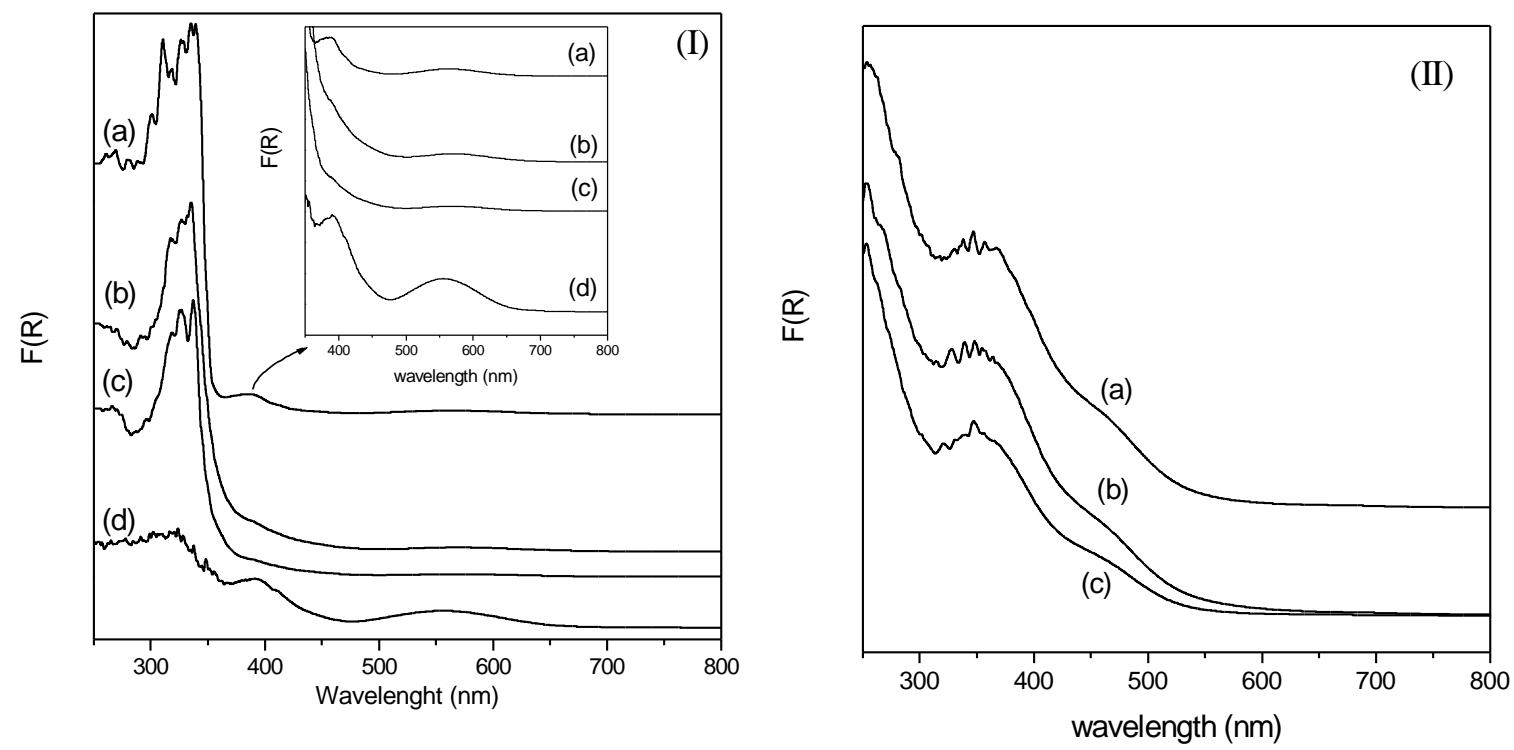

Fig.2. DRS UV-Vis spectra of as-synthesized (I) and calcined (II) catalysts: (a) SBA-0.99I (b) SBA$0.92 \mathrm{G}(\mathrm{c}) \mathrm{SBA}-0.72 \mathrm{G}(\mathrm{d}) \mathrm{Cr}(\mathrm{acac})_{3}$. 
FTIR spectra of chromium supported catalysts and bulk chromium acetylacetonate are shown in Fig. 3. Both grafted an impregnated samples showed typical acetylacetonate ligands band centred at $1525 \mathrm{~cm}^{-1}$ due to the vibration of the $\mathrm{C}=\mathrm{C}$ bonds, bands at 1378 and $1577 \mathrm{~cm}^{-}$ ${ }^{1}$ corresponding to vibration of the $\mathrm{C}=\mathrm{O}$ bonds and one band located at $1425 \mathrm{~cm}^{-1}$ related to the vibration of $\mathrm{C}-\mathrm{H}$ bonds present in $\mathrm{CH}_{3}$ groups [13-14]. Therefore, acetylacetonate ligands retained their ring structure during the interaction with SBA-15 support surface.

Removal of acetylacetonate ligands from the chromium complexes anchored onto the siliceous mesoporous support was studied by TG analysis in airflow (Fig. 4).

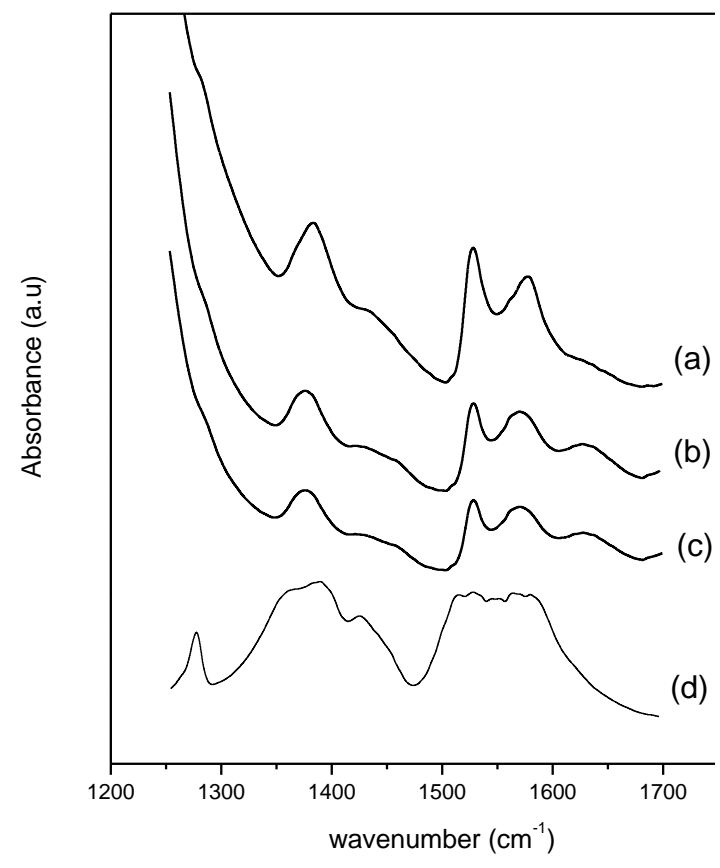

Fig.3. FT- IR spectra of (a) SBA-0.99I (b) SBA-0.92G (c) SBA-0.72G (d) Cr(acac) 3 .
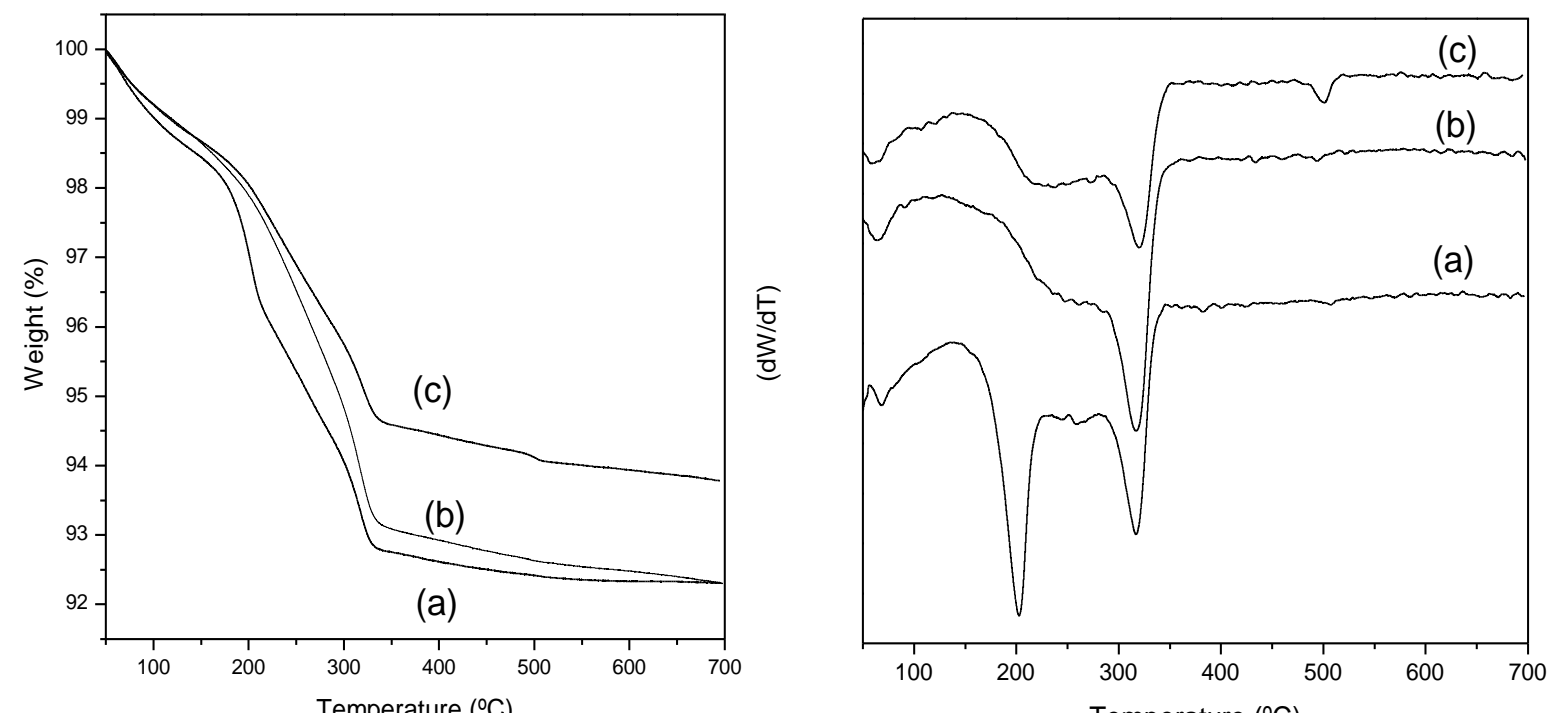

Fig.4. TGA analysis of (a) SBA-0.99I (b) SBA-0.92G (c) SBA-0.72G 
Weight losses associated with acetylacetonate elimination were observed in all samples in the $150-350{ }^{\circ} \mathrm{C}$ temperature range. Taking into account that acac ligands removal was accompanied by oxidation of $\mathrm{Cr}^{3+}$ ions to $\mathrm{Cr}^{6+}$, the observed weight losses can be described as follows [15] :

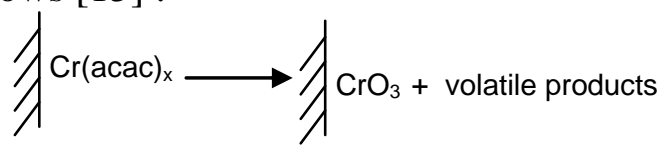

So it is possible to determine " $\mathrm{x}$ " values corresponding to the (acac ligands/chromium ions) ratios in the chromium species anchored to the solid surface. These molar ratios determined by TGA and by elemental analysis, are presented in Table 2.

TABLE 2.

(Acac/Cr) molar ratios calculated by TG and elemental analysis.

\begin{tabular}{ccccc}
\hline \multirow{2}{*}{ Sample } & \multicolumn{2}{c}{ TG Analysis } & \multicolumn{2}{c}{ Elemental } \\
& $\begin{array}{c}\text { Analysis } \\
\text { molar ratio }\end{array}$ & $\begin{array}{c}\text { DTG } \\
\text { Peaks }\left({ }^{\circ} \mathrm{C}\right)\end{array}$ & $\begin{array}{c}\text { Carbon } \\
(\text { wt } \%)\end{array}$ & $\begin{array}{c}\text { (Acac/Cr) } \\
\text { molar ratio }\end{array}$ \\
\hline SBA-0.24G & 3.35 & $250 ; 318$ & 0.82 & 2.95 \\
SBA-0.42G & 3.18 & $250 ; 318$ & n.d. & n.d. \\
SBA-0.72G & 2.97 & $250 ; 318$ & 2.46 & 2.96 \\
SBA-0.92G & 3.18 & $250 ; 318$ & 3.24 & 3.05 \\
SBA-0.99I & 3.00 & $207 ; 318$ & 3.73 & 3.23 \\
\hline
\end{tabular}

n.d. not determined

DTG profile of SBA-0.99I catalysts presented two peaks at 207 and $318{ }^{\circ} \mathrm{C}$, with an (acac/Cr) ratio was close to 3. According to the literature [13-14], the peak at $207^{\circ} \mathrm{C}$ can be attributed to the elimination of acac ligands involved in hydrogen bonding with surface hydroxyls groups, while the second peak could be assigned to the thermal decomposition of acac ligands unfavourably oriented for the interaction with support surface. Therefore, the interaction of $\mathrm{Cr}(\mathrm{acac})_{3}$ with SBA-15 support by the incipient wetness impregnation method, may occur through a H-bonding mechanism between support hydroxyl groups and the quasi П-electron system of the acac ligands (Scheme 1a) [13-14]. This result was in agreement with the preservation of $\mathrm{Cr}(\mathrm{acac})_{3}$ structure deduced from UV-vis spectra (Fig. 2 Ia).

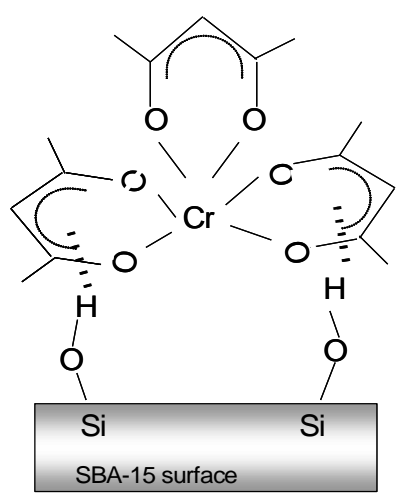

a)

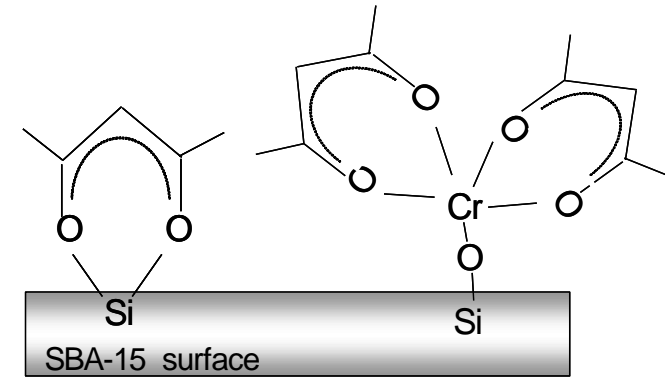

b)

Scheme 1. Proposed mechanisms for the interaction between $\mathrm{Cr}(\mathrm{acac})_{3}$ and SBA-15 surface: a) Hbonding, b) Covalent bonding. 
On the other hand, samples prepared by grafting showed a DTG profile with only one peak at $318{ }^{\circ} \mathrm{C}$ and a shoulder at $250{ }^{\circ} \mathrm{C}$. Again, the (acac/Cr) ratios found were close to 3 . In these catalysts, the absence of the low temperature peak $\left(207^{\circ} \mathrm{C}\right)$ and the greenish colour observed, pointed to no acac ligands hydrogen bonded with surface silanol groups. Based on these evidences, Scheme $1 \mathrm{~b}$ was proposed to describe the interaction of $\mathrm{Cr}(\mathrm{acac})_{3}$ with SBA15 support during the grafting process. Here, chromium is covalently bonded to the SBA-15 surface because of a ligand exchange reaction between acetylacetonate and surface $\mathrm{OH}$ groups $[13,16]$.

\subsection{Activity results in ethylene polymerization.}

Comparative ethylene polymerization reactions were carried out using two catalysts with similar chromium content as SBA-0.99I and SBA-0.92G, prepared by impregnation and grafting methods respectively. Table 3 summarizes catalysts activities and properties of the obtained polymers. It can be observed that polymerization activities clearly depend on catalysts preparation method. So the SBA-0.99G sample prepared by grafting presented similar activity in comparison with conventional $\mathrm{Cr} / \mathrm{SiO}_{2}$ catalysts [17-18]. However, the catalyst prepared by impregnation exhibit a lower activity.

TABLE 3.

Comparison of ethylene polymerization results between impregnated and grafted catalysts

\begin{tabular}{|c|c|c|c|c|c|c|}
\hline \multirow[b]{2}{*}{ Catalyst } & \multirow[b]{2}{*}{$\begin{array}{c}\text { Activity } \\
\text { (g PE/g cat h) }\end{array}$} & \multicolumn{3}{|c|}{ POLYETHYLENE } & \multicolumn{2}{|l|}{ PROPERTIES } \\
\hline & & Mw & $\mathrm{Mw} / \mathrm{Mn}$ & $\begin{array}{c}\text { HLMI } \\
(\mathrm{g} / 10 \mathrm{~min})\end{array}$ & $\begin{array}{l}\text { Bulk Density } \\
(\mathrm{g} / \mathrm{cc})\end{array}$ & $\begin{array}{c}\mathrm{T}_{\mathrm{m}} \\
\left({ }^{\circ} \mathrm{C}\right)^{\mathrm{a}} \\
\end{array}$ \\
\hline SBA-0.99I & 1493 & 426210 & 37.58 & 4.1 & 0.33 & 131.8 \\
\hline SBA-0.92G & 3187 & 362400 & 34.20 & 4.2 & 0.32 & 131.5 \\
\hline
\end{tabular}

${ }^{a}$ Melting temperature measured by DSC

According to the literature [2, 17-19], the differences in activity of both types of catalysts may be related with the presence of lower hydroxyl population and/or more reducible chromium species on the SBA- $0.92 \mathrm{G}$ catalyst surface, since both catalysts (impregnated and grafted) presented very similar textural properties after calcination at $600{ }^{\circ} \mathrm{C}$. Table 3 evidences that the impregnated catalyst leaded to a polymer with higher molecular weight and consequently lower HLMI than polyethylene obtained with grafted catalyst. On the other hand, melting temperatures $\left(\mathrm{T}_{\mathrm{m}}\right)$ of the obtained polymers were slightly lower than typical values of high-density polyethylene $\left(135-140^{\circ} \mathrm{C}\right)$. This fact can be explained by the effect of 1-hexene and hydrogen over polyethylene properties [18].

XRD and FTIR (not show) were also used to characterize the obtained polyethylene with SBA-0.99I and SBA-0.92G catalysts. In both cases, XRD patterns were typical of crystalline polyethylene with [110] and [200] diffraction peaks at $21.6^{\circ}$ and $24^{\circ}$ respectively, [20]. FTIR spectra indicated the characteristics vibrations at 715 and $1473 \mathrm{~cm}^{-1}$ assigned to the methylene groups of PE in their rocking and bending mode. Bands at 2850 and $2919 \mathrm{~cm}^{-1}$ (symmetric and asymmetric methylene stretching modes of polyethylene) were also observed [21].

\section{CONCLUSIONS.}

Ethylene polymerization catalysts have been prepared by grafting and impregnating chromium (III) acetylacetonate onto siliceous SBA-15 swelled mesoporous material. 
Textural properties of the catalysts pointed to a little decrease in surface area and pore volume with chromium incorporation, while pore size remained almost unaltered. The amount of chromium anchored onto the SBA-15 surface increased with grafting solution concentration although low grafting efficiencies $(<10 \%)$ were achieved. The fresh impregnated sample showed the same colour (violet) and UV-vis spectrum, with $\mathrm{Cr}$ (III) d-d bands centred at 325, 390 and $560 \mathrm{~nm}$, than the bulk $\mathrm{Cr}(\mathrm{acac})_{3}$. Nevertheless, uncalcined samples prepared by grafting showed a greenish colour and Uv-vis spectra, where the $390 \mathrm{~nm}$ band had almost disappeared. Calcination of the as-synthesized catalysts resulted in the complete disappearance of $\mathrm{d}$-d bands due to the oxidation of $\mathrm{Cr}(\mathrm{III})$ to $\mathrm{Cr}(\mathrm{VI})$ species.

The interaction of chromium acetylacetonate molecules with the SBA-15 support surface occurs without a loss of acac ligands since the $(\mathrm{acac} / \mathrm{Cr})$ ratios found in the chromium complexes fixed to SBA-15 surface were around three for all the prepared catalysts. The attachment of $\mathrm{Cr}$ species to SBA-15 surface depends on preparation method. Chromium acetylacetonate may preserve its structure in catalyst prepared by impregnation. In this case, the interaction with the support may occur through an H-bonding between support hydroxyl groups and the quasi $\Pi$ electron system of the acac ligands. On the contrary, a ligand exchange reaction may occur during grafting process.

Polymerization activity also depends on catalyst preparation method. For similar chromium content, catalyst prepared by grafting is much more active than catalyst prepared by impregnation. Regarding polymer properties, $\mathrm{Cr} / \mathrm{SBA}-15$ catalyst prepared by impregnation leads to polyethylene with slightly higher molecular weight, polydispersity, bulk density and melting temperature than the polyethylene obtained with the grafted catalyst.

\section{REFERENCES.}

[1] J.P. Hogan, R.L. Banks, Polymerization of olefins. US Patent No 2825721 (1958).

[2] M.P. McDaniel, Ind. Eng. Chem. Res., 27 (1988) 1559.

[3] B.M.Weckhuysen, R. A. Schoonheydt, Catal. Today, 51 (1999) 215.

[4] M. P. McDaniel, Adv. Catal., 33 (1985) 47.

[5] D. Zhao, J. Feng, Q. Huo, N. Melosh , H. Fredrickson, B. Chmelka, G.D. Stucky, Science, 279 (1998) 548.

[6] M.G. White, Catal. Today, 18 (1993) 73.

[7] F.H. Ribeiro, G.A.Somorjai, Recl. Trav. Chim., Pays-Bas, 113 (1994) 419.

[8] S.K. Jana, R. Nishida, K. Shindo, T. Kugita, S. Namba, Micropor. Mesopor. Mater., 68 (2004) 133.

[9] J. C. Kevin, M. G. White, Langmiur, 7 (1991) 1198.

[10] A.B.P. Lever, Inorganic Electronic Spectroscopy, $2^{\text {nd }}$ ed., Elsevier, Amsterdam, 1984.

[11] S. Haukka, E-L Lakomaa, T. Suntola, Appl. Surf. Sci., 75 (1994) 220.

[12] B.M. Weckhuysen, I.E. Wachs, R.A. Schoonheydt, Chem. Rev., 96 (1996) 3327.

[13] I.V.Babich, Y.V. Plyuto, P. Van der Voort, E.F. Vansant, J. Colloid. Interf. Sci., 189 (1997) 144.

[14] I.V.Babich, Y.V. Plyuto, P. Van der Voort, E.F. Vansant, J. Chem. Soc. Faraday Trans., 93 (1997) 3191.

[15] A. Hakuli, A. Kytokivi, Phys. Chem. Chem. Phys., 1 (1999) 1607.

[16] S. Haukkao, E-L Lakomaa, T. Suntola, Appl. Surf. Sci., 75 (1994) 220.

[17] M.P. Mc Daniel, Adv. Catal., 33 (1985) 47.

[18] S.L. Scott, J.Amor Nait Ajjou, Chem. Eng. Sci., 56 (2001) 4155.

[19] M.P. McDaniel, M.B. Welch, J. Catal., 82 (1983) 98.

[20] S.Krimm, A.V. Tobolsky, J. Polym. Sci., 7 (1951) 57.

[21] C.N. Banwell, E.M. Mc Cash, Fundamentals of molecular spectroscopy, $4^{\text {th }}$ ed., Mc Graw-Hill, London, 1994. 